\title{
Exigências térmicas e tabela de vida de fertilidade de Amblyseius largoensis
}

\author{
Thermal requirements and fertility life table of the Amblyseius largoensis
}

\author{
Andréia Serra GalvãoI Manoel Guedes Corrêa Gondim Junior ${ }^{{ }^{*}}$ Gilberto José de Moraes $^{\text {II }}$ \\ José Vargas de Oliveira ${ }^{\mathrm{I}}$
}

RESUMO

Amblyseius largoensis (Muma) (Acari: Phytoseiidae) é uma espécie de ampla distribuição, ocorrendo em regiões tropicais e subtropicais, freqüentemente associada a plantas perenes, sendo um dos principais predadores de Aceria guerreronis Keifer (Acari: Eriophyidae) em coqueiro (Cocos nucifera L.). O objetivo deste trabalho foi determinar as exigências térmicas de A. Iargoensis alimentado com uma combinação de Tetranychus urticae Koch (Acari: Tetranychidae), pólen de Ricinus communis L. e mel a 10\% e elaborar uma tabela de vida de fertilidade. O estudo foi conduzido a 18, 21, 24, 27 e $30^{\circ} \mathrm{C}$, umidade relativa $70 \pm 10$ $\%$ e fotofase de $12 \mathrm{~h}$. Nessas temperaturas, o período de ovoadulto durou 14,$0 ; 8,6 ; 6,1 ; 5,0$ e 3,9 dias, respectivamente. Os estágios de ovo, larva, protoninfa, deutoninfa e período de ovo-adulto apresentaram limiares térmicos de 13,3; 13,3; 13,5; 11,9 e $13,3^{\circ} \mathrm{C}$ e constantes térmicas de 20,$9 ; 13,5 ; 14,9 ; 18,9$ e 66,1 graus-dia. Os parâmetros da tabela de vida de fertilidade foram melhores a 27 e $30^{\circ} \mathrm{C}$.

Palavras-chave: Aceria guerreronis, controle biológico, predador, coqueiro.

\section{ABSTRACT}

Amblyseius largoensis (Muma) (Acari: Phytoseiidae) is a species widely spread and naturally occurring in the tropics and subtropics regions. This species is also associated with perennial plants and considered an important predator of Aceria guerreronis Keifer (Acari: Eriophyidae) in coconut trees (Cocos nucifera L.). The objective of this research was to determinate the thermal requirements of $\boldsymbol{A}$. largoensis fed with a combination of Tetranychus urticae Koch (Acari: Tetranychidae), pollen of Ricinus communis L. and a $10 \%$ honey solution. The study was conducted at 18, 21, 24, 27 and $30^{\circ} \mathrm{C}, 70 \pm 10 \%$ relative humidity and $12 \mathrm{~h}$ photophase. At these temperatures, the period from egg-adult lasted 14.0, 8.6, 6.1, 5,0 e 3.9 respectively. At those temperatures, the threshold temperature for the development of larva, protonynph, deutonymph and egg-adult were 13.3, 13.3, 13.5, 11.9 and $13.3^{\circ} \mathrm{C}$, and the thermal constants were $20.9,13.5,14.9,18.9$ and 66.1 degree-days, respectively. The fertility life table parameters were better in the 27 and $30^{\circ} \mathrm{C}$.

Key words: Aceria guerreronis, biological control, predator, coconut palm.

\section{INTRODUÇÃO}

As perspectivas no controle biológico de ácaros fitófagos, por meio do uso de ácaros predadores da família Phytoseiidae, são promissoras e devem ser exploradas (MORAES, 2002). Amblyseius largoensis (Muma) (Acari: Phytoseiidae) é um predador comumente encontrado em coqueiros (Cocos nucifera L.), freqüentemente associado à Aceria guerreronis Keifer (Acari: Eriophyidae), que é considerada uma das principais pragas desta palmeira (GONDIM JR. \& MORAES, 2001; MORAES \& ZACARIAS, 2002; MORAES et al., 2004b; LAWSON-BALAGBO et al., 2007). Este predador tem sido relatado em coqueiro em Porto Rico (DE LEON, 1965), Ilhas Fiji (GUTIERREZ \& SCHICHA, 1984), Papua Nova Guiné (SCHICHA \& GUTIERREZ, 1985) e no Brasil, no Estado de Pernambuco (GONDIM JR \& MORAES, 2001).

IDepartamento de Agronomia, Área de Fitossanidade, Universidade Federal Rural de Pernambuco (UFRPE). Av. Dom Manoel de Medeiros, s/n, Dois Irmãos, 52171-900, Recife, PE, Brasil. E-mail: mguedes@depa.ufrpe.br.*Autor para correspondência.

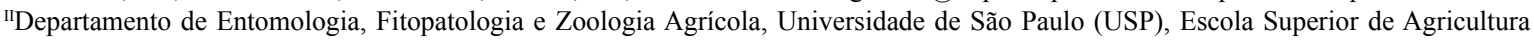
"Luiz de Queiroz", Piracicaba, SP, Brasil. 
Segundo MORAES et al. (2004a), este ácaro é cosmopolita, tendo sido relatado sobre diversas espécies vegetais, em regiões tropicais e subtropicais de vários continentes, exceto na Europa.

Para se avaliar o potencial de uma espécie como agente de controle biológico, é necessário o estudo dos seus requerimentos alimentares e da dieta mais adequada. O desenvolvimento e a reprodução de A. Iargoensis foram estudados em laboratório comparando-se dietas à base de presas isoladamente ou em adição com pólen e mel, verificando-se que a melhor dieta foi à base de presa + pólen + mel, independentemente da espécie de presa, embora o predador tenha tido bom desempenho alimentado exclusivamente com A. guerreronis (GALVÃO et al., 2007). Além disso, cada espécie apresenta requisitos térmicos próprios, que determinam a maior ou a menor adequação desta a um dado ambiente. Como $\boldsymbol{A}$. largoensis é uma espécie de ampla distribuição, ocorrendo em regiões tropicais e subtropicais, é necessária a identificação das melhores condições ambientais, nas quais este predador se desenvolve, para saber em que região ele apresenta maior potencial de utilização para o controle biológico.

Até o momento nenhum trabalho foi realizado sobre as exigências térmicas de $\boldsymbol{A}$. largoensis. Portanto, o objetivo deste trabalho foi determinar as exigências térmicas de $\boldsymbol{A}$. largoensis e elaborar tabelas de vida de fertilidade deste predador, alimentado com Tetranychus urticae Koch (Acari: Tetranychidae) + pólen de mamona (Ricinus communis L.) + mel a 10\%, para avaliar em que condição de temperatura o desempenho do predador é mais favorecido.

\section{MATERIAL E MÉTODOS}

Os predadores utilizados no experimento foram obtidos de coqueiros anões verdes, do banco de germoplasma da Universidade Federal Rural de Pernambuco (UFRPE) $\left(8^{\circ} 01^{\prime}\right.$ latitude Sul e $34^{\circ} 56^{\prime}$ de longitude Oeste). Com estes, foram estabelecidas colônias em unidades constituídas por folíolos de feijão-de-porco (Canavalia ensiformes L.) mantidos sobre uma secção de uma manta de espuma de polietileno que por sua vez era mantida permanentemente úmida, com água destilada. Os predadores foram alimentados com uma mistura de diferentes estágios de $\boldsymbol{T}$. urticae oferecidos com auxílio de um pincel, pólen e mel. O mel foi oferecido umedecendo-se um pedaço de papel toalha de $0,8 \times$ $0,8 \mathrm{~cm}$ colocado sobre uma lamínula de $1,8 \times 1,8 \mathrm{~cm}$. O pólen foi oferecido sobre uma lamínula de mesmo tamanho. As criações foram mantidas a $27 \pm 0,5^{\circ} \mathrm{C}, 70 \pm$
$10 \%$ de UR e $12 \mathrm{~h}$ de fotofase. O alimento foi trocado a cada dois dias. Os ácaros utilizados para o experimento foram obtidos entre a $5^{\circ}$ e a $6^{\circ}$ geração das colônias mantidas em laboratório.

Aproximadamente 250 fêmeas adultas de $\boldsymbol{A}$. largoensis foram transferidas das colônias de manutenção para cada uma das cinco novas unidades (50 fêmeas/unidade) preparadas como anteriormente descrito. Cada unidade foi mantida por oito horas a 18 , $21,24,27$ e $30^{\circ} \mathrm{C}$ e à luz, sempre a $70 \pm 10 \%$ de umidade relativa do ar. Após esse período, as fêmeas foram retiradas e os ovos obtidos continuaram sob as mesmas condições de temperatura e umidade, mas a $12 \mathrm{~h}$ de fotofase. A cada $6 \mathrm{~h}$, os ovos foram examinados para determinação do período de incubação e viabilidade. Após a eclosão, cada larva foi transferida para uma unidade de criação (um disco de folha de $\boldsymbol{C}$. ensiformes de 2,5 $\mathrm{cm}$ de diâmetro sobre um disco de papel de filtro de mesmo diâmetro colocado em uma placa de Petri plástica de $2,6 \mathrm{~cm}$ de diâmetro e $1 \mathrm{~cm}$ de altura, cuja tampa continha um orifício de $0,5 \mathrm{~cm}$ de diâmetro fechado com tela fina). $O$ papel de filtro era diariamente umedecido com água destilada; os discos de folha foram substituídos por novos a cada quatro dias. Os ácaros foram alimentados com a mesma dieta em que foram mantidos nas colônias de manutenção, sendo o alimento complementado diariamente. As observações continuaram a cada seis horas, para determinar a duração dos estágios imaturos e a viabilidade.

Após a emergência, cada fêmea adulta foi transferida, juntamente com um macho proveniente das colônias de manutenção, para uma unidade constituída por um retângulo recortado de um folíolo de feijão-deporco ( $10 \mathrm{~cm}$ de comprimento $\mathrm{x} 5 \mathrm{~cm}$ de largura) mantido sobre uma secção de uma manta de espuma de polietileno; cada retângulo foi circundado por uma faixa de algodão hidrófilo, sendo a espuma e o algodão mantidos úmidos pela adição diária de água destilada, para evitar a fuga dos ácaros. As unidades foram mantidas às mesmas condições em que os imaturos haviam se desenvolvido. A cada $24 \mathrm{~h}$, os ácaros foram examinados para determinar os parâmetros de reprodução. Os machos mortos eram repostos por outros das colônias de manutenção, até a morte da fêmea. Os ovos obtidos a cada dia foram agrupados, sendo a nova geração criada até a fase adulta para determinar a razão sexual.

Os dados de duração da fase imatura e do período total de ovo a adulto obtidos nas cinco temperaturas $\left(18,21,24,27 \mathrm{e} 30^{\circ} \mathrm{C}\right)$ foram submetidos à análise de regressão, por meio do Programa de Regressão do modelo estatístico SAS (SAS Institute, 1989) e os dados referentes à duração dos períodos de 
pré-oviposição, oviposição, pós-oviposição, número total de ovos por fêmea e longevidade de fêmea foram submetidos à análise de variância, sendo as médias comparadas pelo teste de Tukey a 5\% de significância, pelo mesmo programa estatístico. O limite térmico inferior $(\mathrm{Tb})$ e a constante térmica $(\mathrm{K})$ foram calculados pelo Método da Hipérbole, utilizando-se o programa computacional Modelos Bioestatísticos Aplicados a Entomologia (MOBAE) (HADDAD, 1999). O valor de $\mathrm{K}$ foi obtido por meio da fórmula $\mathrm{K}=\mathrm{y}(\mathrm{t}-\mathrm{a})$, sendo $\mathrm{K}=$ constante térmica em graus-dias; $\mathrm{y}=$ tempo requerido, em dias, para completar o desenvolvimento; $\mathrm{T}=$ temperatura em ${ }^{\circ} \mathrm{C} ; \mathrm{a}=$ limiar térmico inferior em ${ }^{\circ} \mathrm{C}$ (SILVEIRA NETO et al., 1976). Os parâmetros da tabela de vida de fertilidade (taxa líquida de reprodução $\left(\mathrm{R}_{\mathrm{o}}\right)$, tempo médio da geração $(\mathrm{T})$, taxa intrínseca de crescimento populacional $\left(\mathrm{r}_{\mathrm{m}}\right)$, taxa finita de crescimento populacional $(\lambda)$ e tempo médio em dias para duplicar a população em números (TD)) foram estimados por meio do programa estatístico SAS (SAS, 1989), adaptando o programa escrito por MAIA et al. (2000), o qual utiliza o método "Jackknife" para estimar intervalos de confiança das médias dos tratamentos e permite comparações entre pares de tratamentos empregandose o teste $\mathrm{t}$.

\section{RESULTADOS E DISCUSSÃO}

O tempo de desenvolvimento dos estágios imaturos de A. largoensis diminuiu com o aumento de temperatura de 18 para $30^{\circ} \mathrm{C}$. A duração dos estágios de ovo, larva, protoninfa e deutoninfa reduziram de 4,3 a 1,2; 2,8 a 0,8; 3,2 a 0,9 e 3,9 a 1,1 dias, respectivamente, entre 18 e $30^{\circ} \mathrm{C}$. A duração do período de ovo a adulto a $18^{\circ} \mathrm{C}$ (14,0 dias) foi cerca de 3,5 vezes mais longo que a $30^{\circ} \mathrm{C}$ (3,9 dias). A análise de regressão entre a temperatura e a duração das fases imaturas de $\boldsymbol{A}$. largoensis mostrou que o modelo matemático que melhor se ajustou foi o quadrático para cada um dos estágios isoladamente e para toda a fase imatura (ovo a adulto), indicando um decréscimo acentuado na duração com aumento das temperaturas inferiores e uma estabilização nas temperaturas superiores (Figura 1).

Os períodos de pré-oviposição, oviposição, pós-oviposição e longevidade também reduziram de forma progressiva da menor para a maior temperatura. Por alguma razão desconhecida, o período de oviposição foi maior a 30 que a $27^{\circ} \mathrm{C}$. Já o número total de ovos por fêmea apresentou padrão de variação contrário, aumentando progressivamente da menor para a maior temperatura, neste caso, não foi significativa a diferença entre 27 e $30^{\circ} \mathrm{C}$. A razão sexual variou de forma irregular entre as diferentes temperaturas, sendo maior a 21,24 e $30^{\circ} \mathrm{C}$ (Tabela 1$)$.
O limite térmico inferior $(\mathrm{Tb})$ para o desenvolvimento de cada estágio imaturo e de toda a fase imatura variou de 13,3 a $13,5^{\circ} \mathrm{C}$, exceto o estágio de deutoninfa, para o qual o valor calculado foi de $11,9^{\circ} \mathrm{C}$. A constante térmica $(\mathrm{k})$ para cada um daqueles estágios e para o período total de ovo a adulto foi de 20,$9 ; 13,5 ; 14,9 ; 18,9$ e 66,1 graus-dia, respectivamente (Figura 2).

Os parâmetros da tabela de vida de fertilidade apresentaram melhores resultados nas temperaturas de 27 a $30^{\circ} \mathrm{C}$, sendo próximos entre si, e não diferindo estatisticamente, exceto para o tempo de geração (T), cujos valores foram de 12,2 e 13,2 dias para 27 e $30^{\circ} \mathrm{C}$, respectivamente (Tabela 2).

Verificou-se neste trabalho que a $27^{\circ} \mathrm{C}$ o predador completou o seu ciclo em cinco dias. Resultado próximo foi encontrado por KAMBUROV (1971), que estudou o desenvolvimento de $\boldsymbol{A}$. largoensis a $26^{\circ} \mathrm{C}$ em várias fontes de alimento: Brevipalpus phoenicis (Geijskes), Tetranychus cinnabarinus (Boisduval), Phyllocoptruta oleivora (Ashmead), Eutetranychus orientalis (Klein), excreções açucaradas e pólen de diversas plantas. Este o autor verificou que o período de desenvolvimento do predador variou de 4,7 a 10 dias, tendo o menor período sido observado quando A. largoensis foi alimentado com $\boldsymbol{E}$. orientalis (4,7 dias), sugerindo dessa forma que a temperatura e o alimento são adequados ao desenvolvimento do predador.

$\mathrm{O}$ efeito da temperatura no desenvolvimento de uma população de $\boldsymbol{A}$. largoensis coletada de folhas de melancia em casa-de-vegetação na Flórida, utilizando somente pólen como alimento foi estudado por YUE \& TSAI (1996). Estes autores verificaram que a $30^{\circ} \mathrm{C}$ as durações das fases de ovo, larva, protoninfa e deutoninfa e o período total de ovo a adulto foram 1,5; 1,$2 ; 1,4 ; 1,3$ e 5,4 dias, respectivamente. Estes autores observaram ainda que o número total de ovos de $\boldsymbol{A}$. largoensis alimentados com pólen de aveia (Avena sativa L.) variou de 16,7 a 34,3 ovos/fêmeas nas temperaturas de 15 a $30^{\circ} \mathrm{C}$, valores próximos aos observados neste trabalho, entretanto, a longevidade das fêmeas a $25^{\circ} \mathrm{C}$ foi de 18,3 dias, dados inferiores aos observados para A. largoensis neste trabalho a $24^{\circ} \mathrm{C}$. Finalmente esses autores determinaram os valores dos parâmetros da tabela de vida de fertilidade, observando que a $25^{\circ} \mathrm{C}$ o predador obteve os melhores resultados de $R_{o}=19,77$ e $r_{m}=0,26$, valores próximos aos encontrados neste trabalho a 27 e $30^{\circ} \mathrm{C}$. Esta comparação sugere que a dieta utilizada neste trabalho (T. urticae, pólen de mamona e mel) seja mais apropriada à A. largoensis que exclusivamente pólen de aveia. 


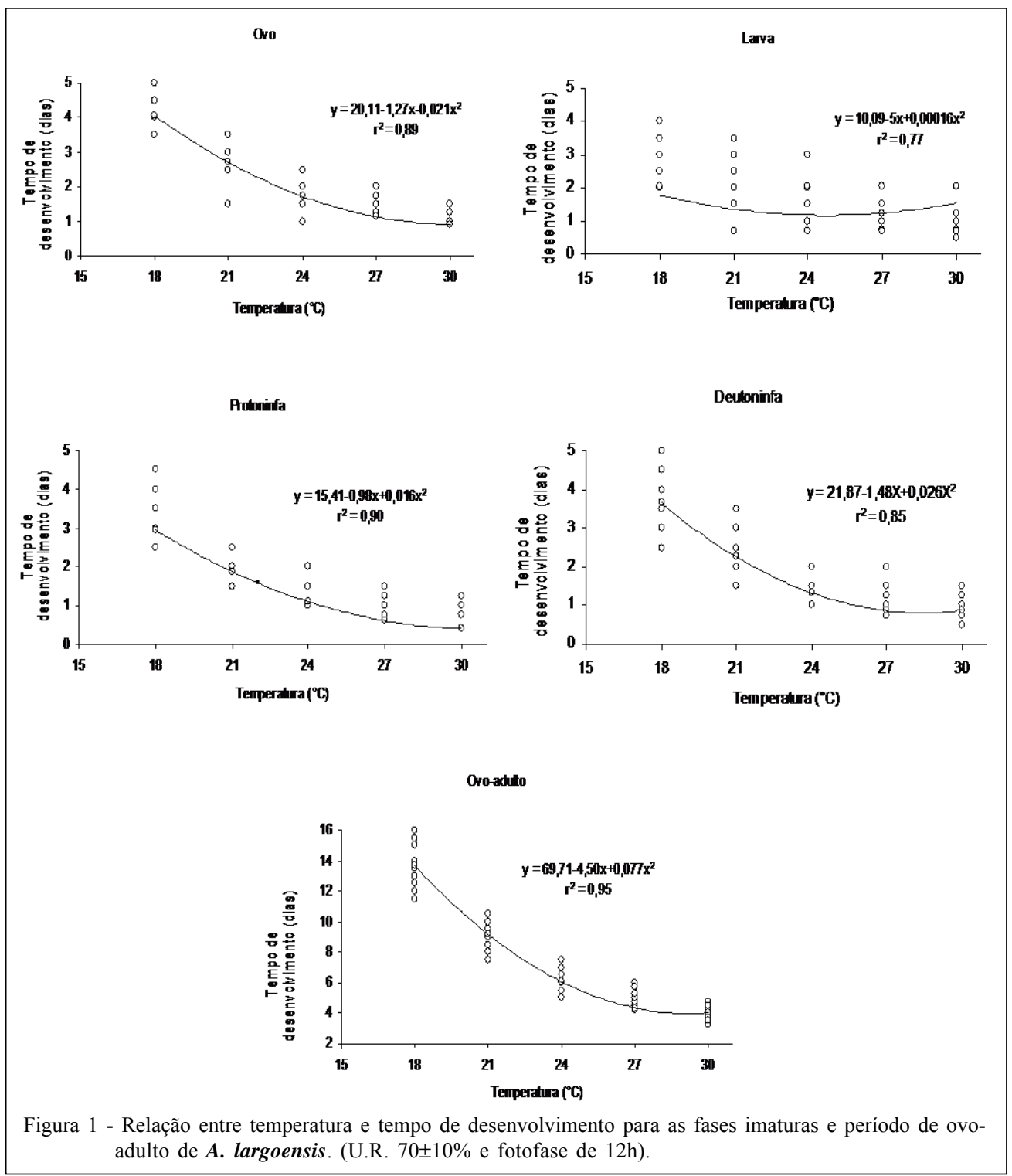

O desenvolvimento de A. largoensis a $21{ }^{\circ} \mathrm{C}$ foi estudado por RODRIGUEZ \& RAMOS (2004), que obtiveram o predador de folhas de citros (Citrus sp.) em Cuba e utilizaram como alimento Polyphagotarsonemus latus (Banks). Estes autores verificaram que aquele predador completou o ciclo em 6,3 dias e consideraram o tarsonemídeo como presa adequada ao seu desenvolvimento, afirmando que o mesmo prefere alimentar-se de formas imaturas de $\boldsymbol{P}$. latus do que dos adultos.

Estudos para determinação dos parâmetros da tabela de vida de fertilidade de $\boldsymbol{A}$. largoensis foram realizados por MORELL \& LIMA (2003) a $23^{\circ} \mathrm{C}$, que alimentaram o predador com pólen de Zea mays (L.) + P. latus. Estes autores obtiveram os valores de $r_{\mathrm{m}}=$
$0,28, \lambda=1,33$ e $R_{0}=17,59$, os quais foram superiores aos obtidos neste trabalho para a temperatura de $24^{\circ} \mathrm{C}$.

Uma característica peculiar de fitoseídeos generalistas, como A. largoensis, é o consumo de vários tipos de alimento, como ácaros fitófagos, pólen de diversas plantas, exsudatos e excreções açucaradas (MCMURTRY \& CROFT, 1997). Para esse predador, o consumo de presas como tetraniquídeos e eriofídeos. juntamente com pólen e excreções açucaradas, melhoram o desempenho de vários parâmetros biológicos como longevidade, número total de ovos por fêmea e sobrevivência (KAMBUROV, 1971). Adieta oferecida neste trabalho proporcionou resultados semelhantes aos verificados por GALVÃO et al. (2007), no desenvolvimento e nos parâmetros da tabela de 
Tabela 1 - Duração média ( \pm EP), em dias, dos períodos de pré-oviposição, oviposição e pós-oviposição, número total de ovos, longevidade de fêmeas e razão sexual de A. largoensis em diferentes temperaturas, U.R. $70 \pm 10 \%$ e fotofase de $12 \mathrm{~h}$.

\begin{tabular}{|c|c|c|c|c|c|}
\hline \multirow[t]{2}{*}{ Parâmetros Biológicos } & 18 & 21 & 24 & 27 & 30 \\
\hline & $\mathrm{n} \phi^{1}=23$ & $\mathrm{n}_{\mathrm{q}}=23$ & $\mathrm{n}_{\mathrm{P}}=27$ & $\mathrm{n}$ o $=37$ & $\mathrm{n}_{\mathrm{p}}=24$ \\
\hline Pré-oviposição & $5,2 \pm 0,13 \mathrm{a}^{2}$ & $3,1 \pm 0,27 \mathrm{~b}$ & $2,2 \pm 0,09 \mathrm{c}$ & $0,9 \pm 0,01 \mathrm{~d}$ & $0,3 \pm 0,09 \mathrm{e}$ \\
\hline Oviposição & $39,8 \pm 0,30 \mathrm{a}$ & $32,1 \pm 0,64 \mathrm{~b}$ & $28,7 \pm 0,45 \mathrm{c}$ & $20,4 \pm 0,58 \mathrm{e}$ & $26,4 \pm 0,40 \mathrm{~d}$ \\
\hline Pós-oviposição & $13,7 \pm 0,42 \mathrm{a}$ & $10,6 \pm 0,55 b$ & $7,7 \pm 0,16 \mathrm{c}$ & $5,3 \pm 0,64 \mathrm{~d}$ & $2,2 \pm 0,21 \mathrm{e}$ \\
\hline Longevidade $o$ & $58,7 \pm 0,55 \mathrm{a}$ & $45,8 \pm 0,57 \mathrm{~b}$ & $38,7 \pm 0,46 \mathrm{c}$ & $26,2 \pm 1,07 \mathrm{~d}$ & $28,8 \pm 0,33 \mathrm{~d}$ \\
\hline $\mathrm{N}^{\mathrm{o}}$ total de ovos & $22,6 \pm 0,43 \mathrm{~d}$ & $26,3 \pm 0,33 \mathrm{c}$ & $29,8 \pm 0,85 \mathrm{~b}$ & $33,2 \pm 0,84 \mathrm{a}$ & $35,3 \pm 0,61 \mathrm{a}$ \\
\hline Razão sexual & $0,71 \pm 0,001 \mathrm{~b}$ & $0,74 \pm 0,004 \mathrm{a}$ & $0,74 \pm 0,001 \mathrm{a}$ & $0,71 \pm 0,003 \mathrm{~b}$ & $0,73 \pm 0,002 \mathrm{a}$ \\
\hline
\end{tabular}

${ }^{1}$ Número de repetições;

${ }^{2}$ Médias não seguidas de mesma letra na linha diferem entre si pelo teste de Tukey a $5 \%$ de significância (SAS, 1989).

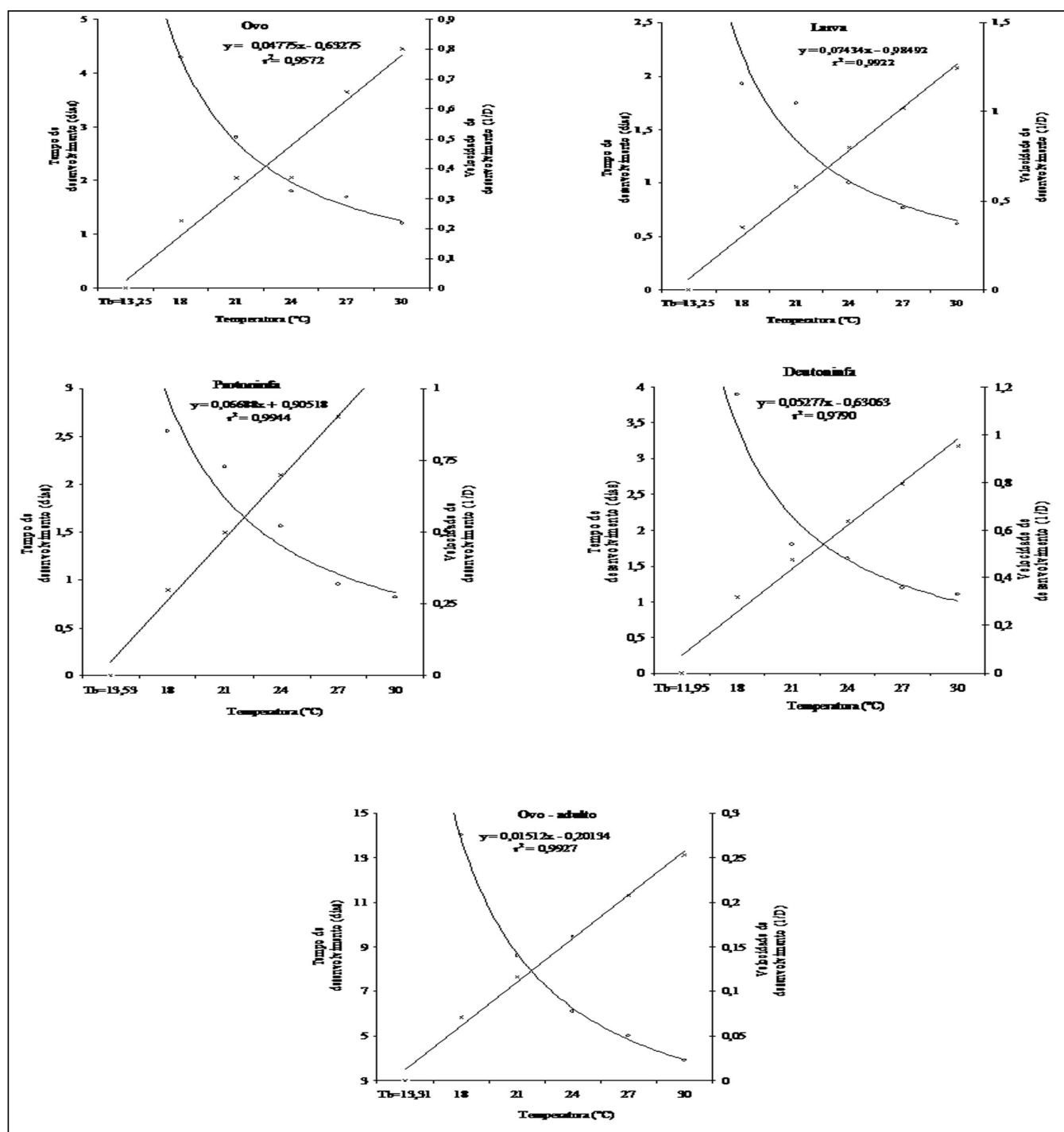

Figura 2 - Relação entre temperatura, tempo de desenvolvimento (o) e velocidade de desenvolvimento $(+)$ das fases imaturas e do período de ovo-adulto de A. Iargoensis (UR) $70 \pm 10 \%$ e fotofase de $12 \mathrm{~h}$ ). 
Tabela 2 - Taxa líquida de reprodução $\left(\mathrm{R}_{\mathrm{o}}\right)$, tempo médio de geração $(\mathrm{T})$, taxa intrínseca de crescimento populacional $\left(\mathrm{r}_{\mathrm{m}}\right)$, taxa finita de crescimento populacional $(\lambda)$ e tempo médio em dias para duplicar a população em números (TD) de A. largoensis, em diferentes temperaturas. UR $70 \pm 10 \%$ e fotofase de $12 \mathrm{~h}$.

\begin{tabular}{|c|c|c|c|c|c|}
\hline Temperatura $\left({ }^{\circ} \mathrm{C}\right)$ & $\begin{array}{c}\mathrm{R}_{\mathrm{o}} \\
\left(\text { () }(\text { (ㅇ })^{-1}\right.\end{array}$ & $\begin{array}{c}\mathrm{T} \\
\text { (dias) }\end{array}$ & $\begin{array}{c}\mathrm{r}_{\mathrm{m}} \\
(\text { O })\left(\text { (O) }^{-1}(\mathrm{dia})^{-1}\right.\end{array}$ & $\lambda$ & $\begin{array}{l}\text { TD } \\
\text { (dias) }\end{array}$ \\
\hline 18 & $\begin{array}{c}11,81 \\
(11,29-12,33) \mathrm{c}\end{array}$ & $\begin{array}{c}31,7 \\
(31,0-32,3) \mathrm{a}\end{array}$ & $\begin{array}{c}0,08 \\
(0,07-0,08) \mathrm{d}\end{array}$ & $\begin{array}{c}1,08 \\
(1,07-1,08) \mathrm{d}\end{array}$ & $\begin{array}{c}8,9 \\
(8,7-9,1) \mathrm{a}\end{array}$ \\
\hline 21 & $\begin{array}{c}15,24 \\
(14,43-16,01) b\end{array}$ & $\begin{array}{c}22,4 \\
(21,9-23,0) b\end{array}$ & $\begin{array}{c}0,12 \\
(0,11-0,12) \mathrm{c}\end{array}$ & $\begin{array}{c}1,12 \\
(1,12-1,13) \mathrm{c}\end{array}$ & $\begin{array}{c}5,7 \\
(5,7-5,8) \mathrm{b}\end{array}$ \\
\hline 24 & $\begin{array}{c}16,79 \\
(15,74-17,85) b\end{array}$ & $\begin{array}{c}18,2 \\
(17,5-18,9) c\end{array}$ & $\begin{array}{c}0,15 \\
(0,15-0,16) b\end{array}$ & $\begin{array}{c}1,17 \\
(1,16-1,17) b\end{array}$ & $\begin{array}{c}4,5 \\
(4,3-4,7) \mathrm{c}\end{array}$ \\
\hline 27 & $\begin{array}{c}19,42 \\
(18,33-20,50) a\end{array}$ & $\begin{array}{c}12,2 \\
(11,8-12,6) \mathrm{e}\end{array}$ & $\begin{array}{c}0,24 \\
(0,23-0,24) \mathrm{a}\end{array}$ & $\begin{array}{c}1,28 \\
(1,27-1,28) \mathrm{a}\end{array}$ & $\begin{array}{c}2,9 \\
(2,8-2,9) \mathrm{d}\end{array}$ \\
\hline 30 & $\begin{array}{c}21,12 \\
(20,25-21,99) a\end{array}$ & $\begin{array}{c}13,2 \\
(12,8-13,7) \mathrm{d}\end{array}$ & $\begin{array}{c}0,23 \\
(0,22-0,24) \mathrm{a}\end{array}$ & $\begin{array}{c}1,27 \\
(1,25-1,27) \mathrm{a}\end{array}$ & $\begin{array}{c}3,0 \\
(2,9-3,1) \mathrm{d}\end{array}$ \\
\hline
\end{tabular}

Médias não seguidas pela mesma letra, na coluna, diferem entre si por meio de comparações de tratamentos dois a dois por meio do intervalo de confiança a $95 \%$ de probabilidade após estimativa de erros pelo método Jackknife (S AS, 1989).

vida de fertilidade de A. largoensis, quando estes autores ofereceram uma combinação de A. guerreronis ou T. urticae + pólen de mamona + mel a $27^{\circ} \mathrm{C}$.

Os resultados relacionados à duração dos estágios imaturos, da longevidade e da fecundidade mostram que o melhor desempenho de A. largoensis foi a $30^{\circ} \mathrm{C}$. Embora os valores de $\mathrm{r}_{\mathrm{m}}, \lambda, \mathrm{T}$ e TD não tenham diferido estatisticamente entre 27 e $30^{\circ} \mathrm{C}$, em valores reais, houve um desfavorecimento destes parâmetros a $30^{\circ} \mathrm{C}$. Portanto, a possível utilização desse predador como agente de controle deve ser mais promissora em regiões com temperaturas médias anuais próximas ou superiores aos $27^{\circ} \mathrm{C}$, como em grande parte do litoral das regiões Norte e Nordeste. Nestes locais, A. largoensis é um potencial inimigo natural de $\boldsymbol{A}$. guerreronis na cultura do coqueiro (GALVÃO et al., 2007; LAWSON-BALAGBO et al., 2008).

\section{CONCLUSÕES}

As melhores condições de temperatura para desenvolvimento e reprodução de $\boldsymbol{A}$. largoensis são entre $27 \mathrm{e} 30^{\circ} \mathrm{C}$.

\section{AGRADECIMENTOS}

À Coordenação de Aperfeiçoamento de Pessoal de Nível Superior (CAPES) e ao Conselho Nacional de Desenvolvimento Científico e Tecnológico ( $\mathrm{CNPq})$, pela concessão da bolsa de estudo à primeira autora, junto ao Programa de Pós-graduação em Fitossanidade/Entomologia da UFRPE. Ao CNPq, pela concessão de bolsa de produtividade em pesquisa aos demais autores.

\section{REFERÊNCIAS}

DE LEON, D. Phytoseiid mites from Puerto Rico with descriptions of new species (Acarina: Mesostigmata). Florida Entomologist, Gainesville, v.48, n.2, p.121-131, 1965.

GALVÃO, A.S. et al. Biologia de Amblyseius largoensis (Muma) (Acari: Phytoseiidae), um potencial predador de Aceria guerreronis Keifer (Acari: Eriophyidae) em coqueiro. Neotropical Entomology, Vacaria, v.36, n.3, p.465-470, 2007.

GONDIM JR, M.G.C.; MORAES, G.J. Phytoseiid mites (Acari: Phytoseiidae) associated with palm trees (Arecaceae) in Brazil. Systematic and Applied Acarology, London, v.6, p.65-94, 2001.

GUTIERREZ, J.; SCHICHA, E. Phytoseiidae and Tetranychoidea in Fiji and other South Pacific Islands (Acari). International Journal of Entomology, Honolulu, v.26, n.4, p.386-388, 1984.

HADDAD, M.L. Métodos para estimar os limites térmicos inferior e superior de desenvolvimento de insetos. Piracicaba: FEALQ, 1999. 29p.

KAMBUROV, S.S. Development and reproduction of Amblyseius largoensis on various food substances. Journal of Economic Entomology, Lanham, v.64, n.3, p.643-648, 1971.

LAWSON-BALAGBO, L.M. et al. Refuge use by the coconut mite Aceria guerreronis: Fine scale distribuition and association with other mites under the perianth. Biological Control, San Diego, v.43, n.1, p.102-110, 2007.

LAWSON-BALAGBO, L.M. et al. Exploration of the acarine fauna on coconut palm in Brazil with emphasis on Aceria guerreronis (Acari: Eriophyidae) and its natural enemies. Bulletin of Entomological Research, Cambridge, v.98, n.1, p.83-96, 2008.

Ciência Rural, v.38, n.7, out, 2008. 
MAIA, A.H.N. et al. Statistical inference on associated fertility life table parameters using Jackknife technique: computational aspects. Journal of Economic Entomology, Lanham, v.93, n.2, p.511-518, 2000 .

MCMURTRY, J.A.; CROFT, B.A. Life styles of phytoseiid mites and their roles in biological control. Annual Review Entomolology, Lanham, v.42, p.91-321, 1997.

MORAES, G.J. Controle biológico de ácaros fitófagos com predadores, In: PARRA, J.R.P. et al. (Eds.). Controle biológico: parasitóides e predadores. São Paulo: Manole, 2002. Cap.4, p.225-237.

MORAES, G.J. et al. A revised catalog of the mite family Phytoseiidae. Zootaxa, Auckland, v.434, p.1-494, 2004a.

MORAES, G.J. et al. Phytoseiid mites (Acari: Phytoseiidae) of coconut growing areas in Sri Lanka, with descriptions of tree new species. Journal of the Acarological Society of Japan, Tsukuba, v.13, n.2, p.1-20, 2004b.

MORAES, G.J.; ZACARIAS, M.S. Use of predatory mites for control of eriophyid mites. In: INTERNATIONAL WORKSHOP ON COCONUT MITE, (Aceria guerreronis). 2002, Sri Lanka. Proceedings... Sri Lanka: Coconut Research Institute, 2002. p.78-88.
MORELL, H.R.; LIMA, M.R. Evaluación de métodos de cria del ácaro Amblyseius largoensis. Manejo Integrado de Plagas y Agroecologia, San José, v.70, p.55-64, 2003.

RODRIGUEZ, H.; RAMOS, M. Biology e feeding behavior of Amblyseius largoensis (Muma) (Acari: Phytoseiidae) on Polyphagotarsonemus latus (Banks) (Acari: Tarsonemidae). Revista de Protección Vegetal, Cuba, v.19, n.2, p.73-79, 2004.

SAS Institute. SAS/STAT ${ }^{\circledR}$ User's guide. Cary NC, 1989. V.2, 846p.

SCHICHA, E.; GUTIERREZ, J. Phytoseiidae of Papua New Guinea, with three new species, and new records of Tetranychidae (Acari). International Journal of Acarology, West Bloomfield, v.11, n.3, p.73-181, 1985.

SILVEIRA NETO, S. et al. Manual de ecologia de insetos. São Paulo: Agrônomica Ceres, 1976. 419p

YUE, B.; TSAI, J.H. Development, survival and reproduction of Amblyseius largoensis (Acari: Phytoseiidae) on selected plant pollens and temperatures. Environmental Entomology, Lanham, v.25, n.2, p.487-494, 1996. 